\title{
COMBINATION OF SGT (SMALL GROUP TEACHING) AND PAL (PEER ASSISTED LEARNING) APPROACH TO FACILITATE LEARNING AMONG MBBS STUDENTS FROM A PRIVATE UNIVERSITY IN MALAYSIA DURING PRE-CLINICAL YEARS
}

\author{
Neena Bhattacharya ${ }^{1}$, Nasrin Habib ${ }^{2}$, Mamunur Rashid ${ }^{2}$, Sandeep Sugathan ${ }^{2}$, Tahmina Afrose ${ }^{1}$ and \\ Ebrahim Nangarath Kottakal ${ }^{2}$ \\ ${ }^{1}$ Faculty of Medicine, AIMST University, Malaysia. \\ ${ }^{2}$ Faculty of Medicine, Quest International University Perak (QIUP), Malaysia
}

Corresponding author: Dr Nasrin Habib

Email: drnh77@gmail.com

\begin{abstract}
Didactic lecture promotes passive learning and fails to motivate students. Small group learning has been widely recommended as it helps to refine understanding of complex issues, to solve the problems, develop critical thinking and apply knowledge to new situations. PALS - a "peer assisted learning" mode where in students discuss in groups and learn from each other. They get motivated and set a platform, which encourages them to communicate and do problem solving. The present study was aimed to evaluate the effectiveness of small group teaching (SGT) and peer assisted learning (PAL) approach among pre clinical medical students. Small groups of students were selected for this study out of the big batch of students pursuing 2nd year MBBS program at AIMST University who were undergoing "respiratory system" block. At the end of lecture-based sessions, a few topics were selected for SGT-PAL session. Students were asked to complete the pretest questions on the selected topics and they were then explained the topics selected for this session. Students had SGT PAL on those selected topics. Then they completed the post test questions on the same topic. Responses obtained for the pre- test and post-test questions were analyzed using SPSS using paired test and the perceptions on their own understanding using marginal homogeneity test, both showed a significant improvement. SGT and PAL approach helped students to improve understanding of important concepts and can be adopted more widely as an alternative to lectures.
\end{abstract}

Keywords: Small group teaching, Peer assisted learning, Pre-clinical, Medical students.

\section{INTRODUCTION}

Lecture method of imparting knowledge has been used for time immemorial. Sitting and listening to an interesting lecture being delivered by a good orator with rich vocabulary and sense of humor is no doubt enjoyable and leaves one spell bound. However, utilizing lecture method for undergraduate teaching learning sessions when at the end of it students are expected to have understood certain important concepts is a difficult goal to achieve. Furthermore when in a lecture hall 200 plus students are expected to understand, explain and apply certain concepts just by listening to a 45 minutes lecture on a certain topic surely is a tall order. Students have to adopt various other means like discussion with peers, teachers or struggle with other resources to achieve the expected learning outcomes.

Although the didactic lecture format may be effective for providing large body of information to a large number of students, it presents many challenges to both teachers and learners, because it often promotes passive learning and fails to motivate students ${ }^{1}$. More importantly how much retention understanding and learning of concepts occurs is a big question. Small group learning has been widely recommended as it gives an opportunity to discuss and refine understanding of complex issues, to problem solve, developcritical thinking and apply knowledge to new situations, and to reflect on attitudes and feelings. Reports consistently favour teaching - learning through small groups ${ }^{2,4,5,6,7}$.

Small group teaching has been drawing a lot of attention in medical education during the last two decades $^{8}$. The effectiveness and advantages of interactive small group teaching (SGT) session over didactic lectures has been receiving tremendous appreciation and is extensively documented ${ }^{9}$. Most of these studies are based on students feedback.

PALS - a "peer assisted learning" mode where in students discuss in groups and learn from each other. They get motivated and set a platform, which encourages them to communicate and do problem solving. PALS havs been utilized in different ways and reports show this to be successful with most students. ${ }^{10,11}$

Student learning is the primary goal of university teaching. Suitable student-oriented teaching methods can help motivate students and help them realize their potential. One of these methods is small group teaching. It is studentcentered and the tutor plays the role of a facilitator $^{3}$ 
The present study was aimed to evaluate the effectiveness of small group teaching (SGT) and peer assisted learning (PAL) approach among pre clinical medical students.

\section{METHODS}

Students pursuing 2 nd year MBBS program at AIMST University undergoing "respiratory system block," were randomly selected for this study. After lecture, a few topics were selected for SGT- PAL session. The topics selected were partial pressure of gases, 02 saturation and Cheyne stokes breathing. A 1 to 2 hour interactive session was conducted by two faculty members who took on the role of facilitators.

A total of 30 students were chosen randomly for this SGT PAL session for 3 topics of respiratory module. They were divided into 3 small groups of 10 each. Selection of students and allocation of students into 3 small groups were done using online random number generation. Students were called PAL leaders and were briefed about the purpose of the session and their responsibility after the session. i.e. of sharing the knowledge with their colleagues. After the lectures on the selected topics, but before the SGT PAL session on the topic, a pretest set of questions, which elicited students' understanding of these selected topics was distributed and their actual level of understanding was obtained. They were asked to rate their understanding of the three topics as poor, good or very good. Anonymity of their responses was maintained.

During the SGT PAL session, the three topics were discussed with the PAL leaders. The discussion was accompanied by demonstration, relevant examples and question answer sessions. At the end of the session students were given the same set of questions as a post-test. The scores of students and their perception on their own understanding levels after the session were collected and analysed using paired t test and marginal homogeneity test respectively with the help of SPSS software.

\section{RESULTS}

A frequency table was generated to see the data dispersion. A cross tabulation was then run to check the consistency of pre and post questions data that the students answered for all 3 parameters.

Table 1: Pre and post test rating by students on their level of understanding of the three selected topics.

\begin{tabular}{|c|c|c|c|c|}
\hline \multicolumn{2}{|c|}{$\begin{array}{l}\text { Pre test students self } \\
\text { evaluation }\end{array}$} & \multicolumn{2}{|c|}{$\begin{array}{l}\text { Post test students self } \\
\text { evaluation }\end{array}$} & \multirow{2}{*}{$\begin{array}{l}\text { Marginal homogeneity test } \\
\qquad \text { P value } \\
<0.01\end{array}$} \\
\hline Poor & $32(35.6 \%)$ & Poor & $3(0 \%)$ & \\
\hline Good & 50 (55.6\%) & Good & 31 (34.4\%) & \\
\hline V.Good & $8(8.8 \%)$ & V.Good & $56(65.6 \%)$ & \\
\hline Total & 90 (100\%) & Total & $90(100 \%)$ & \\
\hline
\end{tabular}

Both pre and post answers were recorded into 3 score scale: Poor $=0$, Good $=1$, and Very good $=$ 2 to grade for every students self-evaluated responses.

Thirty students had participated in this study to get a clear understanding of three topics. Pre test results for the three topics were rated between Poor (32), Good (50), very good (8) and the score in post test changed to Poor(3), Good (31), very good (56) (Table-1). The difference in perception pre test and post test was found to be statistically significant using marginal homogeneity test $(p<0.01)$. The mean value of scores of pretest questions were compared with mean value of scores of posttest questions using paired $t$ test. It showed a significant improvement in post test scores $(p<0.05)$.
The present study reveals a satisfactory outcome when we compare pre test responses with those of post test on level of understanding of the topics after SGT - PAL as compared to pre SGT after a lecture session.

The score changed from good to very good for $67 \%$ of students for partial pressure gases, for $47 \%$ of students in $\mathrm{O} 2$ saturation. In case of Cheyne stokes breathing poor to good response happened in $47 \%$ of students and changed from poor to very good response for $23.4 \%$ students after SGT session (Table-2). The results had shown an overall significant improvement in understanding of the topics after the small group teaching (SGT) session ( $p<0.01$ in marginal homogeneity test) 
Table 2: Percentage change in responses from pre to post test for the three topics

\begin{tabular}{lllll}
\hline Change in score & $\begin{array}{l}\text { Partial pressure of } \\
\text { gases }\end{array}$ & 02 saturation & $\begin{array}{l}\text { Cheyne stokes } \\
\text { breathing }\end{array}$ & Total \\
\hline Poor to Poor & $1(3.3 \%)$ & $1(3.3 \%)$ & $1(3.3 \%)$ & 3 \\
Poor to Good & $2(6.7 \%)$ & $5(16.7 \%)$ & $14(46.7 \%)$ & 21 \\
Poor to V.Good & 0 & $3(10 \%)$ & $7(23.4 \%)$ & 10 \\
Good to Good & $4(13.3 \%)$ & $5(16.7 \%)$ & $1(3.3 \%)$ & 10 \\
Good to V.Good & $20(66.7 \%)$ & $14(46.6 \%)$ & $4(13.3 \%)$ & 38 \\
V.Good to V.Good & $3(10 \%)$ & $2(6.7 \%)$ & $3(10 \%)$ & 8 \\
\hline Total & $30(100 \%)$ & $30(100 \%)$ & $30(100 \%)$ & 90 \\
\hline
\end{tabular}

\section{DISCUSSION}

Many different types of peer assisted learning methods have been utilized which include peer teaching, peer assessment and feedback, peer mentoring and peer leadership.

PAL has been used for many years in the United States of America and has shown higher examination scores, lowered subjective distress and enhanced course satisfaction among students. PAL not only plays a key role in cognitive development and communication skills but also helps boost self-esteem. Many studies have shown that PAL has a positive effect in terms of examination scores ${ }^{10,12 .}$

PAL is attaining considerable importance in medical education particularly due to the constraints on resources, which have forced teachers to create new educational environments that can be delivered at a lower $\cos ^{13}$

We feel strongly that in face of limited resources in terms of number of lecturers and time constraint the concepts attained at the end of lecture session can be improved and strengthen by using SGT and PAL approach. Similar views have been expressed by healthcare and academic staff who are enthusiastic about teaching, but are often restricted by resources and staff numbers. ${ }^{10,13}$

Both educators and students have expressed reservations about using PAL in the clinical environment where as peer-assisted learning is a common feature of the pre-clinical learning environment ${ }^{14,15}$ This may be due to a lack of knowledge or a lack of explicit training in teaching and feedback delivery. A common concern is that PAL may be disruptive, place strain on friendships and relationships between the students, and endenger competition. To increase the effectiveness of peer assisted learning in medical schools, some important aspects which cover organizational issues, tutorintere selection, training of the tutor, and running and evaluating the sessions are described bffonflict Weyrich et al. Advantages of small group interactive sessions have been reported widely ${ }^{15,16,17,18 .}$

Success stories with PAL have been reported in preclinical environments and clinical environments, showing as good as or better performance in examinations. ${ }^{2,17,19,20,21,2}$

Our experience with SGT \&PAL approach for important in understanding of some of the concepts in physiology has been quite rewarding and we would recommend utilization of this approach and also to introduce such sessions as a regular feature in the existing preclinical curriculum. We have been looking for some way to reinforce concepts delivered during didactic lectures in a classroom with 200 plus students. It is indeed difficult for the students to understand some of the complex yet important concepts presented during the lecture session particularly when the concentration level of students keeps fluctuating. This trial of combining small group teaching with PAL approach seems to have provided one solution.

GT session while our purpose of reinforcement of some concepts gets full filled, additionally active involvement of students in their own learning further helps in improving their communication skills, motivation and interest in the subject. Further improvement in their understanding of the subject and also of communication skills is expected when they cascade the knowledge gained to their peers.

\section{REFERENCES}

1. Chandelkar, RataboliP.V, KulkarniM.S. assessment of impact of small group teaching over didactic lectures and self-directed learning among second year bds students in general and dental pharmacology in goa medical college.http://pharmacologyonline.sila e.it 2014; 3:51-57 
2. Bosse, H. M., Nickel, M., Huwendiek, S., Jünger, J., Schultz, J. H., \& Nikendei, C.(2010). Peer role- play and standardised patients in communication training: A comparative study on the student perspective on acceptability, realism, and perceived effect. BMC Medical Education, 10. Retrieved from http: / /www. biomedcentral.com/14726920/10/2

3. Bakhtiyar $\mathrm{NH}$, Norouzi R. New educational methods in the third millennium. Ghom: Sama; 2003.

4. JAQUES, D (2004) Small Group Teaching, Oxford Centre for Staff and Learning Development, UK.

5. Rathnakar UP, Sheetal DU, Preethi GP, Rojeshwari S, Pemminati S, Shiraprakash G,et al. Is small group teaching among the undergraduate dental students really effective. JCDR. 2011;5(4):822-5.

6. Sultan Ayoub Meo.Basic steps in establishing effective small group teaching sessions in medical schools. Pak J MedSci.2013Jul-Aug;29(4):10711076

7. JonesRW.Learning and teachingin small groups: Characteristics, benefits, problems and approaches. AnaesthIntensiveCare.2007; 35(4):587592

8. Euliano TY. Small group teaching: clinical correlation with a human patient simulator. Advances in Physiology Education Published 1 March 2001 Vol. 25 no. 1, 36-43

9. Abubakir M. Saleh, Namir G. Al-Tawil ., et al. Didactic Lectures and Interactive Sessions in Small Groups: A Comparative Study among Undergraduate Students in Hawler College of Medicine, British Journal of Education, Society \& Behavioural Science 3(2): 144-153, 2013.

10. Heckmann JG, Dütsch M, Rauch C, Lang C, Weih M, Schwab S. Effects of peerassisted training during the neurology clerkship: a randomized controlled study. Eur J Neurol 2008; 15:1365-70.

11. Patterson,L.J., 2013, What are the effects of peer assisted learning strategies on reading acheivements in elementary students in an urban area.
12. Glass N, Walter R. An experience of peer mentoring with student nurses: enhancement of personal and professional growth. J Nurs Educ 2000; 39:155-60.

13. Yu T, Wilson NC, Singh PP, Lemanu DP, Hawken SJ, Hill AG. Medical students as teachers: a systematic review of peer assisted teaching during medical school. Adv Med Educ Pract 2011; 2:157- 72.

14. Krych, A. J., March, C. N., Bryan, R. E., Peake, B. J., Pawlina, W., \& Carmichael, S. W. (2005). Reciprocal peer teaching: students teaching students in the gross anatomy laboratory. Clinical Anatomy, 18(4), 296-301.

15. Weyrich $P$, Schrauth $M$, Kraus $B$, Hebermehl D, Netzhammer N, Zipfel S, et al. Undergraduate technical skills training guided by students tutors: analysis of tutor's attitudes, tutees acceptance and learning progress in an innovative teaching model. BMC Med Edu 2008; 9:8-

16. Huang R. Chinese International Students' perceptions of the problembased learning experience. JoHLSTE. 2005;4(2):36-43.

17. MacauleyR, BillingsJA. Teaching small groupsinpalliativecare. JPalliatMed.2011Jan;14(1):91-5

18. CurranVR, SharpeD, ForristallJ. et al. Student satisfaction and perceptions of small group process in case-based inter professional learning. MedTeach.2008;30(4):431-3.

19. Calhoon, M., Otaiba, S., Greenberg, D., King, A., \& Avalos, A. (2006). Improving reading skills in predominantly Hispanic title 1 first-grade classrooms: the promise of peer-assisted learning strategies. Learning Disabilities Research \& Practice, 21(4), 261-273. Pl

20. Knobe, M., Münker, R., Sellei, R. M., Holschen, M., Mooij, S. C., SchmidtRohlfing, B., Pape, H. C. (2010). Peer teaching: A randomised controlled 71 Tai, Haines, Canny, and Molloy trial using student- teachers to teach musculoskeletal ultrasound. Medical Education, 44(2), 148-155.

21. Lave, J., \& Wenger, E. (1991). Situated practice: Legitimate peripheral participation. Cambridge, England: Cambridge University Press. 
22. Ross MT, Cameron HS. Peer assisted learning: a planning and implementation framework: AMEE Guide no. 30. Med Teach 2007; 29:527-45. 